\title{
An Evolutionary Firefly Algorithm, Goal Programming Optimization Approach for Setting the Osmotic Dehydration Parameters of Papaya
}

\author{
Ting Cao, Julian Scott Yeomans* \\ OMIS Area, Schulich School of Business, York University, Toronto, Canada \\ Email:tcao16@schulich.yorku.ca, ${ }^{\star}$ syeomans@schulich.yorku.ca
}

How to cite this paper: Cao, T. and Yeomans, J.S. (2017) An Evolutionary Firefly Algorithm, Goal Programming Optimization Approach for Setting the Osmotic Dehydration Parameters of Papaya. Journal of Software Engineering and Applications, 10, 128-142.

https://doi.org/10.4236/jsea.2017.102007

Received: December 10, 2016

Accepted: February 4, 2017

Published: February 7, 2017

Copyright $\odot 2017$ by authors and Scientific Research Publishing Inc. This work is licensed under the Creative Commons Attribution International License (CC BY 4.0).

http://creativecommons.org/licenses/by/4.0/

\begin{abstract}
An evolutionary nature-inspired Firefly Algorithm (FA) is employed to set the optimal osmotic dehydration parameters in a case study of papaya. In the case, the functional form of the dehydration model is established via a response surface technique with the resulting optimization formulation being a non-linear goal programming model. For optimization, a computationally efficient, FA-driven method is employed and the resulting solution is shown to be superior to those from previous approaches for determining the osmotic process parameters. The final component of this study provides a computational experimentation performed on the FA to illustrate the relative sensitivity of this evolutionary metaheuristic approach over a range of the two key parameters that most influence its running time-the number of iterations and the number of fireflies. This sensitivity analysis revealed that for intermediateto-high values of either of these two key parameters, the FA would always determine overall optimal solutions, while lower values of either parameter would generate greater variability in solution quality. Since the running time complexity of the FA is polynomial in the number of fireflies but linear in the number of iterations, this experimentation shows that it is more computationally practical to run the FA using a "reasonably small" number of fireflies together with a relatively larger number of iterations than the converse.
\end{abstract}

\section{Keywords}

Firefly Algorithm, Non-Linear Goal Programming, Process Parameter Optimization, Osmotic Dehydration, Papaya

\section{Introduction}

The global agricultural production of fruits and vegetables is a multi-trillion 
dollar enterprise. The annual worldwide production of papayas currently exceeds 12 million.tonnes [1]. As with many agricultural commodities, the high moisture content of papayas renders them highly perishable and, due to various chemical, microbial, and enzymatic reactions, they commence decomposition immediately upon harvesting [2] [3]. It is, therefore, imperative to establish effective preservation techniques to maintain the overall quality of the produce. This is often achieved through various combinations of heat processing and dehydration methods [4]. From an operational perspective, the dehydration of perishable agricultural produce reduces shipping weights, minimizes their packaging requirements, and permits longer storage periods [5]. However, due to inconsistent product quality, conventionally hot-air dried products using vacuum, tray, and cabinet dryers have not received universal acclaim [5] [6] [7].

Osmotic dehydration techniques have been introduced as an effective alternative that yields higher quality end products than traditional drying approaches [8]. In osmotic dehydration, the produce is placed into a hypertonic solution where water is withdrawn from the produce into the solution due to the differences in their respective concentrations [8]. In this manner, osmotic dehydration removes a portion of the water from the produce thereby creating a product of intermediate moisture content [9] [10]. A concurrent transfer of the solid materials suspended in the hypertonic liquid-such as sugar and salt-also takes place between the solution and the product [8] [11] [12]. Beneficially, osmotic processing contributes only minimal thermal degradation to the nutrients due to the relatively low temperature water removal process in comparison to all standard hot air drying practices [2] [8] [13] [14].

Additionally, osmotic dehydration can also be employed as a pre-treatment to supplemental dry-processing methods as it improves numerous functional, nutritional, and sensory properties of fresh produce [15]. The quality of the subsequent product is superior to one without pre-treatment due to 1) increases in the solid gain transfer of sugar and salt from the solution, 2) the improvements to texture of the fruits and vegetables, and 3) the stability of the colour pigmentation during storage [5] [13]. Thus, in conjunction with other follow-on drying technologies, osmotic dehydration produces a superior quality, shelf-stable product for both local consumption and export markets.

Water removal during the dehydration process is influenced by many factors such as the concentration and type of osmotic agents, temperature, circulation/ agitation of solution, solution-to-sample ratio, thickness of food material, and pre-treatment [6] [8]. While an expanding market currently exists for osmoconvective dehydrated produce in both domestic and world markets, only limited attention has been paid to the optimization of the requisite osmotic processing parameters [5] [13] [16]-[21]. Specifically, an analysis of the mass transport measured in terms of water loss and solid (sugar, salt) gains occurring within the osmosis process is of considerable "real-world" significance [6] [8] [12].

Consequently, in this study, the functional form of the osmotic dehydration 
process is initially determined using response surface techniques [20] [21] [22] [23]. It will be shown that the ensuing optimization model can be represented by a non-linear goal programming formulation [16]-[21]. The study then investigates the impacts of using the evolutionary Firefly Algorithm (FA) [25] [26] [27] to set the optimal osmotic process parameters for the papaya dehydration case introduced in [13]. It will be shown that the ensuing solutions calculated by the FA for the osmotic parameters are superior to those determined by previous approaches. The final component of the study provides a comprehensive computational experimentation performed on the FA using the osmotic dehydration models from the case to determine the relative sensitivity of this evolutionary, nature-inspired metaheuristic over a range of the two key parameters that most influence its running time-the number of iterations and the number of fireflies.

\section{Functional Form and Mathematical Model of the Osmotic Dehydration Process}

The initial section of this study examines the papaya case dehydration from [13]. The first step requires the formulation of a suitable model of the process responses to the three main osmotic drying parameters-1) syrup solution concentration, 2) duration of osmosis, and 3) solution temperature-on the solid gain and water loss of the papaya. This functional representation will be subsequently used to project the solid gain and water loss impacts in the dehydrated papaya over the experimental ranges of the three drying parameters. Once an appropriate formulation has been constructed, the second step is to optimize this model to determine the optimum solid gain and the maximum water loss achievable during osmotic dehydration. In the subsequent model formulation, let $C$ be the hypertonic syrup solution concentration measured in ${ }^{\circ} \mathrm{Brix}, D$ be the duration of the osmosis in hours, and $T$ represent the hypertonic syrup solution temperature in ${ }^{\circ} \mathrm{C}$. For the corresponding response variables, let $S G$ represent the solid gain of the product and $W L$ be the percentage of water loss during the dehydration process. In the papaya case, $S G$ represents the sugar gain percentage in the dehydrated papaya.

Response surface procedures are statistical techniques frequently used for optimization in empirical studies [22] [23] [24]. Response surfaces employ quantitative data in appropriately designed experiments to simultaneously ascertain the various variable relationships within multivariate problems [24]. The equations constructed describe the effect of various test variables on responses, determine interrelationships among the test variables and represent the combined effect of all test variables in any response. Response surfaces enable an experimenter to undertake an efficient exploration of a process or system [23] [24]. These approaches have frequently been used in the optimization of food processes [5] [13] [28] [29] [30] [31] and will, consequently, be employed in this study to determine the appropriate mathematical representation. The proposed model can then be used to predict the water loss and sugar gain in the dehydration of papaya over the different experimental ranges for the process durations, 
syrup concentrations and syrup solution temperatures.

It should be explicitly noted that any mathematically exact representation of the relationship between the osmotic drying parameters in the dehydration process remains unknown. However, a response surface approach permits an empirical approximation to the unknown mathematical model using appropriate experimental design techniques [23] [24]. The specific experimental design comprises the three parameters $(T, C, D)$ each fixed at three levels using data from [13] to determine the corresponding sugar gain $(S G)$ and water loss ( WL) responses. The actual response surface experimental design for the various combinations of input variables and response variable levels requires the fifteen combinations shown in Table 1 (see [13]).

The experimental values for the corresponding response variables $W L$ and $S G$ appear in last two columns of Table 2.

The empirically determined functional equations for the respective response variables, based upon the appropriate response surface experimental design applied to the sugar gain and water loss outputs of Table 2 [16]-[24], are:

$$
\begin{gathered}
W L=63.745-1.56275 T-0.6615 C-6.075 D+0.0286 T^{2}+0.00925 C^{2}+0.79 D^{2}(1) \\
S G=13.9088-0.83028 T-0.04488 C+0.5125 D+0.0106 T^{2}+0.00283 T C
\end{gathered}
$$

In the food industry, organoleptic properties refer to sensory aspects including taste, sight, smell, touch, dryness, moisture content, and stale-fresh factors. Reference [13] established organoleptic ranges for the osmotic dehydration parameters and restricted their search for best parameter settings to values within these ranges. In order to find values for the osmotic dehydration parameters, a number of contour plots were constructed by changing the values of the three

Table 1. Response surface experimental design layout for 3 variables and 3 levels.

\begin{tabular}{ccccccc}
\hline $\begin{array}{c}\text { Treatment } \\
\text { No. }\end{array}$ & $\begin{array}{c}\text { Level for } \\
\mathrm{T}\end{array}$ & $\begin{array}{c}\text { Temperature } \\
\left({ }^{\circ} \mathrm{C}\right)\end{array}$ & $\begin{array}{c}\text { Level for } \\
\mathrm{C}\end{array}$ & $\begin{array}{c}\text { Concentration } \\
\left({ }^{\circ} \text { Brix }\right)\end{array}$ & $\begin{array}{c}\text { Level for } \\
\mathrm{D}\end{array}$ & $\begin{array}{c}\text { Duration } \\
(\text { Hrs })\end{array}$ \\
\hline 1 & 1 & 50 & 1 & 70 & 0 & 5 \\
2 & 1 & 50 & -1 & 50 & 0 & 5 \\
3 & -1 & 30 & 1 & 70 & 0 & 5 \\
4 & -1 & 30 & -1 & 50 & 0 & 5 \\
5 & 1 & 50 & 0 & 60 & 1 & 6 \\
6 & 1 & 50 & 0 & 60 & -1 & 4 \\
7 & -1 & 30 & 0 & 60 & 1 & 6 \\
8 & -1 & 30 & 0 & 60 & -1 & 4 \\
9 & 0 & 40 & 1 & 70 & 1 & 6 \\
10 & 0 & 40 & 1 & 70 & -1 & 4 \\
11 & 0 & 40 & -1 & 50 & 1 & 6 \\
12 & 0 & 40 & -1 & 50 & -1 & 4 \\
13 & 0 & 40 & 0 & 60 & 0 & 5 \\
14 & 0 & 40 & 0 & 60 & 0 & 5 \\
15 & 0 & 40 & 0 & 60 & 0 & 5 \\
\hline
\end{tabular}


variables and observing the effects that these changes instigated in their corresponding response functions [13]. By superimposing the various contours onto a single figure, they visually determined best values for the temperature, concentration, and duration as $37^{\circ} \mathrm{C}, 60^{\circ} \mathrm{Brix}$ and 4.25 hours, respectively. These settings invoked responses of $4.0 \%$ for the sugar gain and $28 \%$ for the water loss (see Table 3).

\section{A Goal Programming Formulation for Setting Osmotic Dehydration Parameters}

The process for finding the best values for the dehydration parameters could be considered analogous to a multi-response optimization and can, therefore, be transformed into an equivalent mathematical programming approach [21]. In this section, this transformation will be achieved by converting the parameter setting process into a corresponding goal programming format.

Based upon the organoleptic requirements for the response functions and parameters established in [13], the technical constraints for the problem can be stated as:

$$
\begin{gathered}
23.02 \leq W L \leq 44.5 \\
2.56 \leq S G \leq 8.1 \\
30 \leq T \leq 50 \\
50 \leq C \leq 70 \\
4 \leq D \leq 6
\end{gathered}
$$

Table 2. Experimental data for water loss and sugar gain under different treatments.

\begin{tabular}{ccccc}
\hline Temperature $\left({ }^{\circ} \mathrm{C}\right)$ & Concentration $\left({ }^{\circ}\right.$ Brix $)$ & Duration $(\mathrm{Hrs})$ & Water Loss $(\%)$ & Sugar Gain $(\%)$ \\
\hline 50 & 70 & 5 & 44.5 & 8.1 \\
50 & 50 & 5 & 35.2 & 5.5 \\
30 & 70 & 5 & 31.7 & 4.5 \\
30 & 50 & 5 & 23.6 & 3.0 \\
50 & 60 & 6 & 44.5 & 8.2 \\
50 & 60 & 4 & 39.6 & 7.0 \\
30 & 60 & 6 & 27.2 & 3.9 \\
30 & 60 & 4 & 23.2 & 2.5 \\
40 & 70 & 6 & 37.8 & 4.8 \\
40 & 70 & 4 & 34.8 & 4.3 \\
40 & 50 & 6 & 28.4 & 4.4 \\
40 & 50 & 4 & 25.7 & 3.4 \\
40 & 60 & 5 & 29.7 & 4.3 \\
40 & 60 & 5 & 30.0 & 4.3 \\
40 & 60 & 5 & 30.2 & 4.4 \\
\hline
\end{tabular}

Table 3. Best osmotic dehydration parameters determined by reference [13].

\begin{tabular}{ccccc}
\hline Temperature $\left({ }^{\circ} \mathrm{C}\right)$ & Concentration $\left({ }^{\circ}\right.$ Brix $)$ & Duration $(\mathrm{Hrs})$ & Water Loss (\%) & Sugar Gain (\%) \\
\hline 37 & 60 & 4.25 & 28 & 4.0 \\
\hline
\end{tabular}


Supplemental organoleptic criteria can be added to the variables and responses for the solution. The objective requirements and targets for these additional desired preferences have been summarized in Table 4. From a hierarchical achievement perspective, several of these preferences can be recognized as more important criteria to attain than the others. Specifically, the water loss needs to be as high as possible within the indicated range from a dehydration perspective, while the sugar gain ought to be as close to $4 \%$ as possible from a taste perspective. The relative importance for attaining these hierarchy targets is displayed in the last column of Table 4.

Therefore, from a mathematical programming standpoint, each desired target can be quantified as a tentative goal and the entire problem can transformed into a conventional goal programming formulation. In the ensuing mathematical programming formulation, a percentage deviation objective function weighted by the relative importance of each goal is employed to penalize deviations from the desired targets. Consequently, the problem for determining osmotic dehydration parameter values can be represented by the subsequent non-linear goal programming model.

Minimize

$$
W_{1} * P_{1}+W_{2} * P_{2}+W_{3} * P_{3}+W_{4} * N_{4}+W_{5} *\left(P_{5}+N_{5}\right)
$$

subject to

$$
\begin{gathered}
P_{1}=T-30 \\
N_{1}=50-T \\
P_{2}=C-50 \\
N_{2}=70-C \\
P_{3}=D-4 \\
N_{3}=6-D \\
N_{4}=44.05-W L \\
P_{4}=W L-23.02 \\
N_{5}=4.00-S G \\
P_{5}=S G-4.00 \\
N_{6}=8.1-S G \\
P_{6}=S G-2.56 \\
P_{i} \geq 0, N_{i} \geq 0 \quad i=1,2,3,4,5,6
\end{gathered}
$$

Table 4. Ranges for process variables and response goals in the osmotic dehydration.

\begin{tabular}{cccccc}
\hline Parameter & Goal & Requirement & Lower Limit & Upper Limit & Relative Importance \\
\hline Temperature $\left({ }^{\circ} \mathrm{C}\right)$ & 1 & Minimize & 30 & 50 & Important \\
Concentration $\left({ }^{\circ} \mathrm{Brix}\right)$ & 2 & Minimize & 50 & 70 & Important \\
Duration (Hrs) & 3 & Minimize & 4 & 6 & Important \\
Water Loss (\%) & 4 & Maximize & 23.02 & 44.05 & Very Important \\
Sugar Gain (\%) & 5 & Target $=4.0$ & 2.56 & 8.1 & Extremely Important \\
\hline
\end{tabular}


Several deviation variables have been introduced in order to complete the transformation of the problem into the series of defined goals. Specifically, let $P_{i}$ and $N_{i}, i=1$ to 6 , correspond to the positive and negative deviations, respectively, from the various goal targets and constraint limits shown in Table 4. Let $W_{i}$ represent weighting factors applied to goal $i, i=1$ to 5 , that denote the relative importance in achieving that goal's target. Without loss of generality, each $W_{i}$ simultaneously includes an appropriate denominator constant necessary to convert the deviation values into requisite deviation percentages. Thus, solving the goal programming model would be equivalent to setting optimal parameter values for the osmotic dehydration process.

\section{A Goal Programming, Firefly Algorithm-Driven Optimization Approach}

While numerous different analytical methods could have been employed, the solution approach actually applied to the resulting optimization problem uses the FA technique. For optimization, it has demonstrated that an FA is more computationally efficient than other such commonly-used metaheuristics as enhanced particle swarm optimization, genetic algorithms, and simulated annealing [26]. Hence, an FA procedure can be considered very computationally efficient. Whereas this section briefly summarizes the FA approach, more detailed explanations can be accessed in [25] and [26].

An FA procedure is a biologically-inspired, population-based, evolutionary metaheuristic in which each firefly within the population represents a potential solution to the problem. The FA employs three idealized rules: 1) All fireflies within a population are unisex, so that one firefly will be attracted to other fireflies irrespective of their sex; 2) Attractiveness between fireflies is proportional to their brightness, implying that for any two flashing fireflies, the less bright one will move towards the brighter one; and 3) The brightness of a firefly is determined by the value of its objective function. For a maximization problem, the brightness can be considered proportional to the value of the objective function. Reference [26] demonstrates that the FA approaches the global optima whenever the number of fireflies $n \rightarrow \infty$ and the number of iterations $t$, is set so that $t \gg 1$. In reality, the FA has been shown to converge extremely quickly into both local and global optima [25] [26]. The basic operational steps of the FA are summarized in Figure 1 [26].

In the FA, there are two important aspects to resolve: the formulation of attractiveness and the variation of light intensity. In a straightforward manner, it can be assumed that the attractiveness of a firefly is associated with its brightness which in turn is determined by the value of the encoded objective function. In the simplest instance, the brightness of a firefly at a location $\boldsymbol{X}$ would be determined by its calculated objective value $F(\boldsymbol{X})$. However, the attractiveness, $\beta$, between fireflies is relative and will vary with the distance $r_{i j}$ between firefly $i$ and firefly $j$. In addition, light intensity decreases with the distance from its source, and light is also absorbed in the media, so the attractiveness should be 
Objective Function $F(X), X=\left(x_{1}, x_{2}, \ldots x_{d}\right)$

Generate the initial population of $n$ fireflies, $X_{i}, i=1,2, \ldots, n$

Light intensity $I_{i}$ at $\boldsymbol{X}_{i}$ is determined by $F\left(X_{i}\right)$

Define the light absorption coefficient $\gamma$

while ( $\mathrm{t}<$ MaxGeneration)

for $i=1: n$, all $n$ fireflies

for $j=1: n$, all $n$ fireflies (inner loop)

if $\left(I_{i}<I_{j}\right)$, Move firefly i towards $\mathrm{j}$; end if

Vary attractiveness with distance $r$ via $\mathrm{e}^{-\gamma r}$ end for $j$

end for $i$

Rank the fireflies and find the current global best solution $G$ end while

Postprocess the results

Figure 1. Pseudo code of the firefly algorithm.

allowed to vary with the degree of absorption. Consequently, the overall attractiveness of a firefly can be defined as

$$
\beta=\beta_{0} \exp \left(-\gamma r^{2}\right)
$$

where $\beta_{0}$ is the attractiveness at distance $r=0$ and $\gamma$ is the fixed light absorption coefficient for a specific medium. If the distance $r_{i j}$ between any two fireflies $i$ and $j$ located at $\boldsymbol{X}_{i}$ and $\boldsymbol{X}_{i}$, respectively, is calculated using the Euclidean norm, then the movement of a firefly $i$ that is attracted to another more attractive (i.e. brighter) firefly $j$ is determined by

$$
X_{i}=X_{i}+\beta_{0} \exp \left(-\gamma\left(r_{i j}\right)^{2}\right)\left(X_{i}-X_{j}\right)+\alpha \varepsilon_{i} .
$$

In this expression of movement, the second term is due to the relative attraction and the third term is a randomization component. Reference [26] indicates that $\propto$ is a randomization parameter normally selected within the range $[0,1]$ and $\varepsilon_{i}$ is a vector of random numbers drawn from either a Gaussian or uniform (generally $[-0.5,0.5]$ ) distribution. It should be pointed out that this expression is a random walk biased toward brighter fireflies and if $\beta_{0}=0$, it becomes a simple random walk. The parameter $\gamma$ characterizes the variation of the attractiveness and its value determines the speed of the algorithm's convergence. For most applications, $\gamma$ is typically set between 0.1 to 10 [26]. For all computational approaches for the FA considered in this study, the variation of attractiveness parameter $\gamma$ is fixed at 5 while the randomization parameter $\propto$ is initially set at 0.6 , but is then gradually decreased to a value of 0.1 as the procedure approaches its maximum number of iterations (see [26]).

By optimizing the goal programming problem formulation using the FA-driven procedure, best process parameters for the osmotic dehydration of the papaya were determined and these resulting values are displayed in Table 5. In comparison to the values found by [13], it can be observed that, while the temperature parameter remains essentially the same, the syrup concentration 
Table 5. Optimal process parameters determined for the osmotic dehydration of papaya.

\begin{tabular}{lccccc}
\hline \multicolumn{5}{c}{ Temperature $\left({ }^{\circ} \mathrm{C}\right)$ Concentration $\left({ }^{\circ}\right.$ Brix $)$ Duration $($ Hrs $)$ Water Loss (\%)Sugar Gain $(\%)$} \\
\hline Reference [13] & 37 & 60 & 4.25 & 28 & 4.0 \\
FA Solution & 37.776 & 70 & 4 & 32.8 & 4.02
\end{tabular}

has increased by $10^{\circ}$ Brix and the duration of dehydration process has been reduced slightly by 0.25 hours. More significantly, in terms of the key response variables, while the sugar gain has remained at the highly desirable target of $4 \%$, the water loss has increased by $5 \%$. Consequently, since the water loss responsewhich is obviously the fundamental feature of the osmotic dehydration process-has been increased significantly from that determined by [13], this goal programming solution represents a significant improvement.

In any given optimization problem, for a very large number of fireflies $n \gg k$ where $k$ is the number of local optima, the initial locations of the $n$ fireflies should be distributed as uniformly as possible to ensure that a comprehensive search throughout the search domain occurs. As the FA proceeds, the fireflies should converge into all of the local optima, including the global ones. By comparing the best solutions among all these optima, the global optima can easily be determined. As noted above, the FA approaches the global optima whenever the number of fireflies $n \rightarrow \infty$ and the number of iterations $t$, is set so that $t \gg 1$ [26]. In reality, the FA has a tendency to converge very quickly into both local and global optima [25] [26] [32].

In general, the two parameters that most directly impact the solution search time of the FA are the values selected for $n$ and $t$. Using terminology from computational complexity, the running time for the FA is linear in $t$, but is second order polynomial in $n$. Obviously, for practical applications, the desire is to be able to determine the best solution in the shortest amount of time. This would correspond to setting $n$ and $t$ at the minimum possible values that produce the best solution(s). However, since the FA's search process evolves from one population to the next and incorporates random components within its solution search, the parameter setting is clearly not a strictly deterministic issue-determining appropriate values for $n$ and $t$ reflects a component of choice on the part of the decision-maker.

Consequently, for the dehydration of papaya case, an ensuing, post-optimization sensitivity analysis was performed to investigate the impact for different combinations of the number of fireflies, $n$, and the number of iterations, $t$, on the solution quality. Specifically, the value of the firefly parameter was set at $n=$ $20,50,100,150,200,250,250,500$ and the value for the number of iterations was set at $t=100,250,500,1000,1500,2500$. For 30 runs of each parametric combination of fireflies and iterations, the corresponding responses for the water loss and sugar gain were recorded. The average values of these responses over the 30 runs per combination are provided in Table 6 and visual representation of these values appears in Figure 2 and Figure 3, respectively.

As might have been anticipated, a priori, it can be observed that more stable 
Table 6. Average sugar gain (\%) and water loss (\%) for different parameter settings of the firefly algorithm.

\begin{tabular}{|c|c|c|c|c|c|c|c|c|c|c|c|c|}
\hline \multirow{3}{*}{$\begin{array}{c}\text { No. of } \\
\text { Fireflies }\end{array}$} & \multicolumn{12}{|c|}{ Number of Iterations } \\
\hline & \multicolumn{2}{|c|}{100} & \multicolumn{2}{|c|}{250} & \multicolumn{2}{|c|}{500} & \multicolumn{2}{|c|}{1000} & \multicolumn{2}{|c|}{1500} & \multicolumn{2}{|c|}{2500} \\
\hline & $S G$ & $W L$ & $S G$ & $W L$ & $S G$ & $W L$ & $S G$ & $W L$ & $S G$ & $W L$ & $S G$ & $W L$ \\
\hline 20 & 4.55 & 33.71 & 4.60 & 33.71 & 4.72 & 34.25 & 4.32 & 33.12 & 4.25 & 33.60 & 4.30 & 33.79 \\
\hline 50 & 4.23 & 32.24 & 4.49 & 33.83 & 4.57 & 33.98 & 4.19 & 33.38 & 4.03 & 32.81 & 4.02 & 32.80 \\
\hline 100 & 4.31 & 33.65 & 4.14 & 33.14 & 4.15 & 33.23 & 4.02 & 32.80 & 4.02 & 32.80 & 4.02 & 32.80 \\
\hline 150 & 4.27 & 33.63 & 4.32 & 33.85 & 4.02 & 32.80 & 4.02 & 32.79 & 4.02 & 32.80 & 4.02 & 32.80 \\
\hline 200 & 4.17 & 33.21 & 4.02 & 32.79 & 4.02 & 32.80 & 4.02 & 32.80 & 4.02 & 32.80 & 4.02 & 32.80 \\
\hline 250 & 4.41 & 34.08 & 4.02 & 32.80 & 4.02 & 32.80 & 4.02 & 32.80 & 4.02 & 32.79 & 4.02 & 32.80 \\
\hline 500 & 4.11 & 33.10 & 4.02 & 32.80 & 4.02 & 32.80 & 4.02 & 32.80 & 4.02 & 32.80 & 4.02 & 32.80 \\
\hline
\end{tabular}

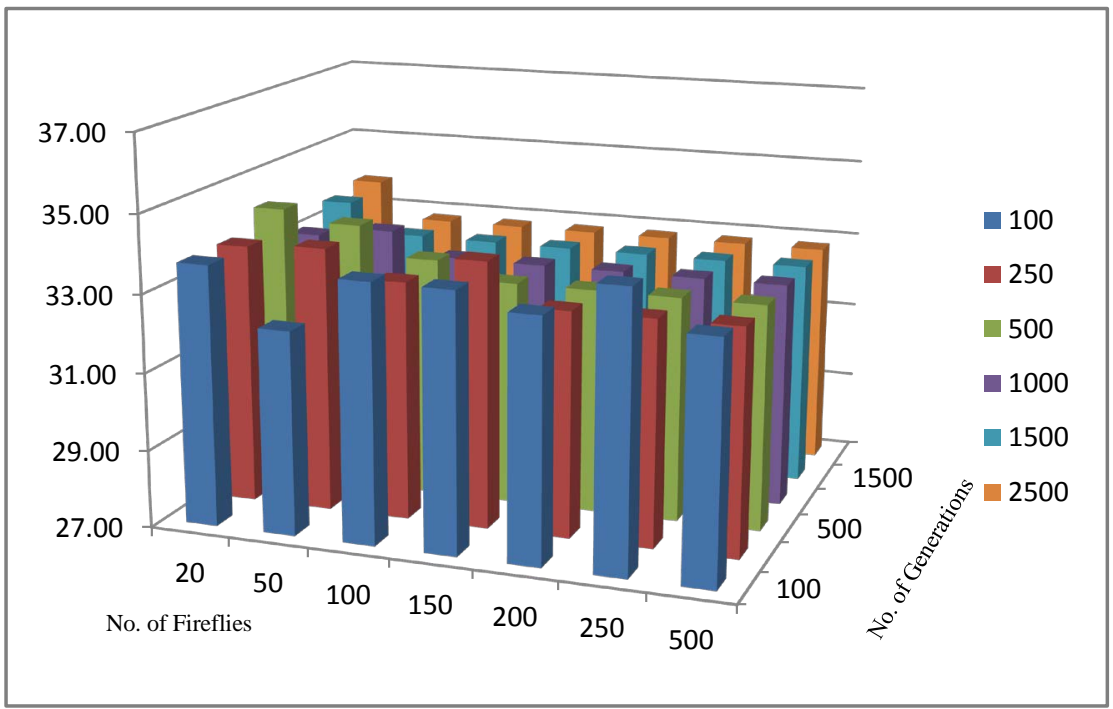

Figure 2. Average water loss (\%) in the papaya for different parameter settings of the firefly algorithm.

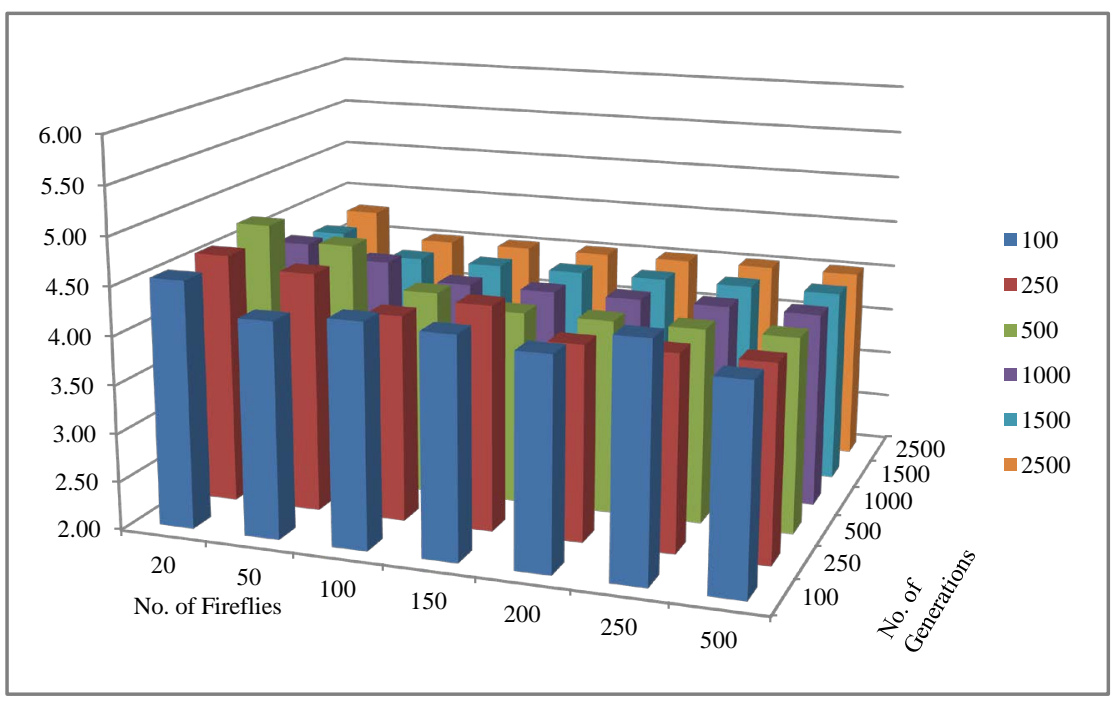

Figure 3. Average sugar gain (\%) in the papaya for different parameter settings of the firefly algorithm. 
solutions (i.e. those where the average values are closer to optimal) are obtained when both the number of fireflies and the number of iterations are larger. More explicitly, larger values of $n$ or $t$ produce on average the actual optimal solution, while experimental combinations involving smaller parameter values produce more solution variability for both the water loss and sugar gain. While there are multiple approaches that could be taken to analyze these results, Figure 4 and Figure 5 provide visual comparisons of the average water loss and sugar gain responses obtained for the minimum and maximum number of iterations considered in the experimentation. From Figure 4 and Figure 5, it can be observed that at $t=2500$, the FA always produces the optimal water loss and sugar gain solution, on average, for any number of fireflies other than $n=20$ (i.e. the FA always generated the optimal solution in each of the 30 runs). Conversely, at $t=$ 100 , the average water loss and sugar gain values indicate that there can be

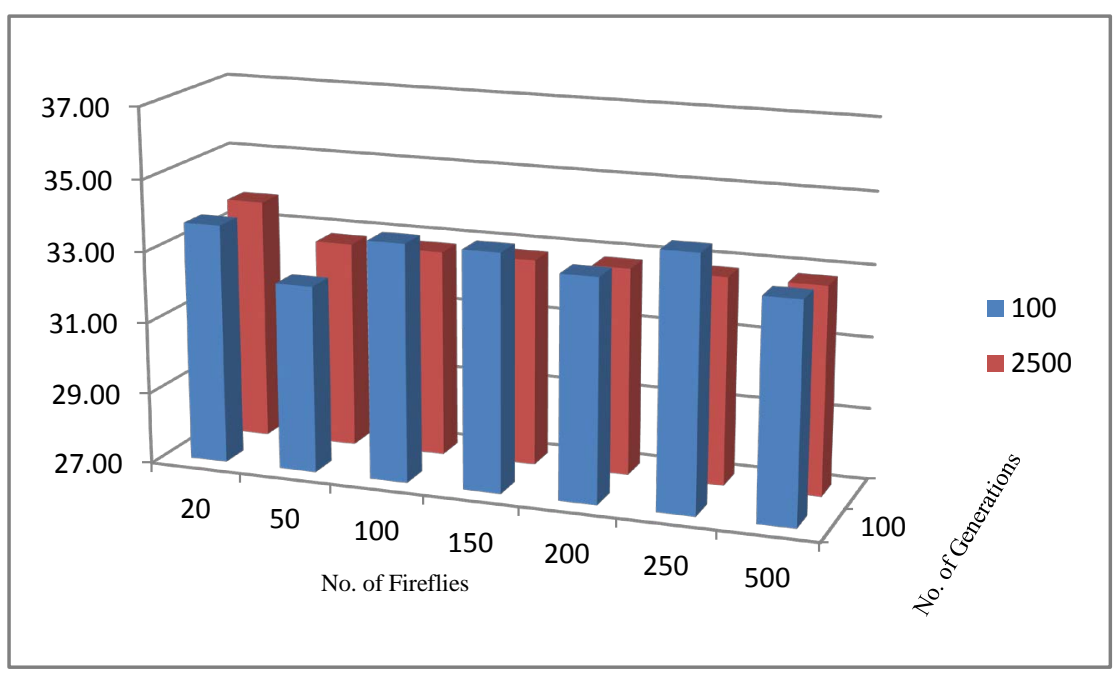

Figure 4. Comparison of average water loss (\%) in the papaya from runs of 100 generations and 2500 generations in the firefly algorithm.

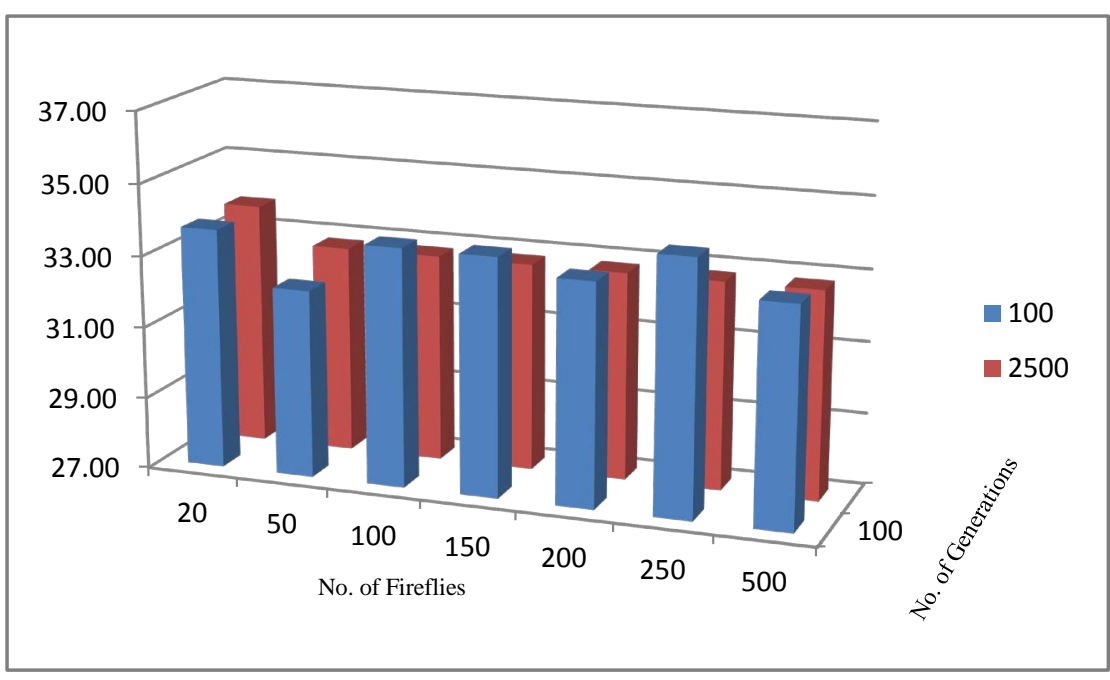

Figure 5. Comparison of average sugar gain (\%) in the papaya from runs of 100 generations and 2500 generations in the firefly algorithm. 
variability in the quality of the solution obtained irrespective of the number of fireflies employed in the FA process. This implies that the more iterations used, the better the solution quality obtained by the FA.

Similarly, Figure 6 and Figure 7 provide a contrast of the average water loss and sugar gain responses based upon the minimum and maximum number of fireflies employed. From the Figures, it can be seen that at $n=500$ fireflies, the

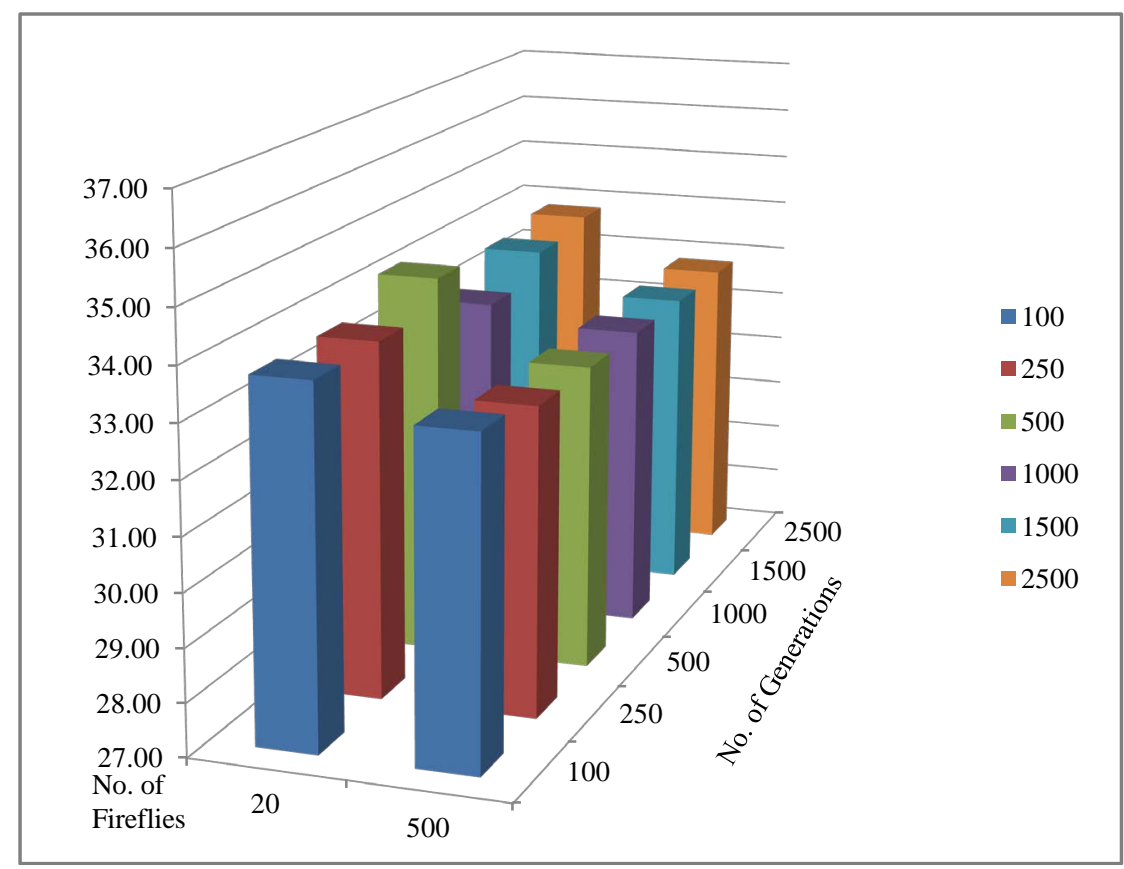

Figure 6. Comparison of average water loss (\%) in the papaya from runs with 20 fireflies and runs with 500 fireflies.

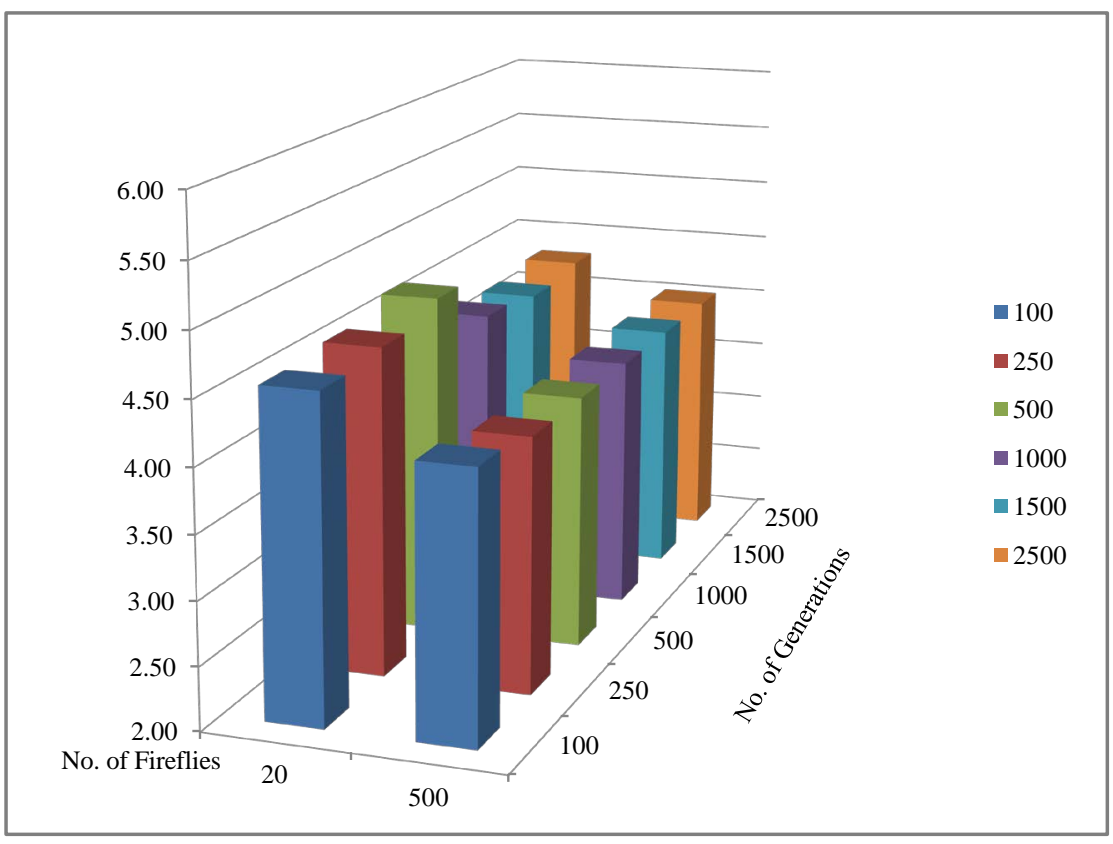

Figure 7. Comparison of average sugar gain (\%) in the papaya between runs with 20 Fireflies and runs with 500 fireflies. 
FA always produces the optimal water loss and sugar gain solutions, on average, for any number of iterations other than $t=100$. Furthermore, even at $t=100$, the average solution value is extremely close to the optimal solution. Conversely, at $n=20$ fireflies, the average water loss and sugar gain values show that there can be considerable variability in the quality of the solution obtained irrespective of the number of iterations of the FA. These findings clearly demonstrate that the more fireflies used in the FA, the better the solution quality.

It needs to be emphasized that Table 6 shows the average response values for each combination of $n$ and $t$. While the FA in the larger parameter value combinations always converged to the overall optimal solution, the smaller combinations would also frequently produce this optimal value within the set of the 30 runs. However, there would also be occasions where deviating solution values were obtained in some of the runs, thereby distorting the overall averages. Consequently, given the computational complexities of the key running time parameters of the FA, a combination of a relatively smaller value of $n$ combined with a relatively larger value for $t$ would be preferable from both a solution time and solution accuracy perspective. Table 6 also highlights that even the relatively intermediate values in the experimental ranges considered for $n$ and $t$ tend to consistently produce very high quality solutions. The specific experimentation on this particular problem indicates that the value for $t$ needs to be somewhere in the range of 500 to 1000 iterations, while the value for $n$ should be set between 100 and 150 fireflies if calculating the true optimal solution is always required.

\section{Conclusion}

In this paper, the functional form of the osmotic dehydration responses for papaya was established using an empirical response surface approach and the resulting optimization formulation was shown to be a non-linear goal programming problem. Subsequently, an evolutionary FA-directed algorithm was used to find the optimal solution to the goal programming model. The osmotic drying parameters determined by the FA were superior to the solutions found by all previous computational approaches. A sensitivity analysis of the osmotic dehydration model demonstrated the relative impact on the FA of the key runningtime parameters of the number of iterations and the number of fireflies. This sensitivity analysis revealed that for intermediate-to-high values of either of these two key parameters, the FA would always determine overall optimal solutions, while lower values of either parameter would generate greater variability in solution quality. Since the running time complexity of the FA is polynomial in the number of fireflies but linear in the number of iterations, this experimentation would therefore suggest that it is more computationally practical to run the FA using a "reasonably small" number of fireflies together with a relatively larger number of iterations than the converse. Since the FA can clearly be adapted to solve a wide spectrum of problems beyond the perishable produce domain, the practicality of this computational approach and the subsequent sensitivity findings can clearly be extended into numerous other practical applications. Such "real 
world" extensions will be the focus of future investigations.

\section{References}

[1] Geohive (2014) Geohive World Crop Production. www.geohive.com/charts/ag_crops.aspx

[2] Sodhi, N.S, Singh, N. and Komal, K. (2006) Osmotic Dehydration Kinetics of Carrots. Journal of Food Science and Technology, 43, 374-376.

[3] Venturini, M.E., Reyes, J.E., Rivera, C.S., Oria, R. and Blanco, D. (2011) Microbiological Quality and Safety of Fresh Cultivated and Wild Mushrooms Commercialized in Spain. Food Microbiology, 28, 1492-1498.

https://doi.org/10.1016/j.fm.2011.08.007

[4] Ranganna, S. (1986) Handbook of Analysis and Quality Control for Fruits and Vegetable Products. Tata McGraw Hill Publishing, New Delhi.

[5] Mehta, B.K., Jain, S.K., Sharma, G.P., Mugdal, V.D., Verma, R.C., Doshi, A. and Jain, H.K. (2012) Optimization of Osmotic Drying Parameters for Button Mushroom (Agaricus bisporus). Applied Mathematics, 3, 1298-1305. https://doi.org/10.4236/am.2012.330186

[6] Rosa, M.D. and Giroux, F. (2001) Osmotic Treatments and Problems Related to the Solution Management. Journal of Food Engineering, 49, 223-236. https://doi.org/10.1016/S0260-8774(00)00216-8

[7] Jain, S.K. and Verma, R.C. (2003) Osmotic Dehydration: A New, Promising and Emerging Industry. Beverage and Food World, 30, 30-34.

[8] Rastogi, N.K., Raghavarao, K.S.M.S., Niranjan, K. and Knorr, D. (2002) Recent Developments in Osmotic Dehydration: Method to Enhance Mass Transfer. Food Science Technology, 13, 48-59. https://doi.org/10.1016/S0924-2244(02)00032-8

[9] Hawkes, J. and Fink, J.M. (1978) Osmotic Concentration of Fruit Slices Prior to Dehydration. Food Processing Preservation, 2, 265-267. https://doi.org/10.1111/j.1745-4549.1978.tb00562.x

[10] Shukla, B.D. and Singh, S.P. (2007) Osmo-Convective Drying of Cauliflower, Mushroom and Green Pea. Food Engineering, 80, 741-747. https://doi.org/10.1016/j.jfoodeng.2006.06.025

[11] Tonon, R.V., Baroni, A.F. and Hubinges, M.D. (2007) Osmotic Dehydration of Tomato in Ternary Solutions: Influence of Process Variables on Mass Transfer Kinetics and an Evaluation of the Retention of Arytenoids. Food Engineering, 82, 509517. https://doi.org/10.1016/j.jfoodeng.2007.03.008

[12] Nieto, A., Castro, M.A. and Alzamora, A. (2001) Kinetics of Moisture Transfer during Air Drying of Blanched and/or Osmotically Dehydrated Mango. Journal of Food Engineering, 50, 175-185. https://doi.org/10.1016/S0260-8774(01)00026-7

[13] Jain, S.K., Verma, R.C., Murdia, L.K., Jain, H.K. and Sharma, G.P. (2011) Optimization of Process Parameters for Osmotic Dehydration of Papaya Cubes. Food Science and Technology, 48, 211-217. https://doi.org/10.1007/s13197-010-0161-7

[14] Kar, A. and Gupta, D.K. (2001) Osmotic Dehydration Characteristics of Button Mushrooms. Journal of Food Science and Technology, 38, 352-357.

[15] Torreggiani, D. and Bertolo, G. (2001) Osmotic Pretreatments in Fruit Processing: Chemical, Physical and Structural Effects. Journal of Food Engineering, 49, 247253. https://doi.org/10.1016/S0260-8774(00)00210-7

[16] Imanirad, R. and Yeomans, J.S. (2015) A Parametric Testing of the Firefly Algorithm in the Determination of the Optimal Osmotic Drying Parameters for Papaya. IEEE Symposium Series on Computational Intelligence, 12, 14-19. 
[17] Imanirad, R. and Yeomans, J.S. (2015) Fireflies in the Fruits and Vegetables: Combining the Firefly Algorithm with Goal Programming for Setting Optimal Osmotic Dehydration Parameters of Produce. In: Yang, X.-S., Ed., Recent Advances in Swarm Intelligence and Evolutionary Computation, Springer, Heidelberg, 49-69. https://doi.org/10.1007/978-3-319-13826-8 3

[18] Yeomans, J.S. (2014) Computing Optimal Food Drying Parameters Using the Firefly Algorithm. Journal on Computing, 4, 40-44.

[19] Yeomans, J.S. (2014) Establishing Optimal Dehydration Process Parameters for Papaya by Employing a Firefly Algorithm, Goal Programming Approach. International Journal of Engineering Research and Applications, 4, 145-149.

[20] Yeomans, J.S. (2015) Determining Optimal Osmotic Dehydration Process Parameters for Papaya: A Parametric Testing of the Firefly Algorithm for Goal Programming Optimization. Scientia Agriculturae, 10, 127-136.

[21] Yeomans, J.S. and Yang, X.S. (2014) Determining Optimal Osmotic Drying Parameters Using the Firefly Algorithm. International Conference on Applied Operational Research (ICAOR), Vancouver, 29-31 July 2014, 32-39.

[22] Box, G.E. and Behnken, D.W. (1960) Some New Three Level Designs for the Study of Quantitative Three Variables. Technometrics, 2, 455-475. https://doi.org/10.1080/00401706.1960.10489912

[23] Myers, R.H. and Montgomery, D.C. (1995) Response Surface Methodology: Process and Product Optimization Using Designed Experiments. John Wiley and Sons, New York.

[24] Montgomery, D.C. (1997) Design and Analysis of Experiments. 4th Edition, John Wiley and Sons, New York.

[25] Imanirad, R., Yang, X.S. and Yeomans, J.S. (2013) Modelling-to-Generate-Alternatives via the Firefly Algorithm. Journal of Applied Operational Research, 5, 14-21.

[26] Yang, X.S. (2010) Nature-Inspired Metaheuristic Algorithms. 2nd Edition, Luniver Press, Frome.

[27] Yeomans, J.S. and Yang, X.S. (2014b) Municipal Waste Management Optimization Using a Firefly Algorithm-Driven Simulation-Optimization Approach. International Journal of Process Management and Benchmarking, 4, 363-375. https://doi.org/10.1504/IJPMB.2014.065518

[28] Alam, M.S., Singh, A. and Sawhney, B.K. (2010) Response Surface Optimization of Osmotic Dehydration Process for Aonla Slices. Food Science Technology, 47, 47-54. https://doi.org/10.1007/s13197-010-0014-4

[29] Mudhar, G.S., Toledo, R.T., Floros, J.D. and Jen, J.J. (1989) Optimization of Carrot Dehydration Process Using Response Surface Methodology. Journal of Food Science, 54, 714-719. https://doi.org/10.1111/j.1365-2621.1989.tb04688.x

[30] Shi, L., Xue, C.H., Zhao, Y., Li, Z.J., Wang, X.Y. and Luan, D.L. (2008) Optimization of Processing Parameters of Horse Mackerel (Trachurus Japonicus) Dried in a Heat Pump Dehumidifier Using Response Surface Methodology. Food Engineering. 87, 74-81. https://doi.org/10.1016/j.jfoodeng.2007.11.010

[31] Uddin, M.B., Amsworth, P. and Ibanoglu, S. (2004) Evaluation of Mass Exchange during Osmotic Dehydration of Carrots Using Response Surface Methodology. Food Engineering, 65, 473-477. https://doi.org/10.1016/j.jfoodeng.2004.02.007

[32] Yeomans, J.S. (2012) Simulation-Driven Optimization in Waste Management Facility Expansion Planning. Journal of Computational Methods in Sciences and Engineering, 12, 111-127. 
Submit or recommend next manuscript to SCIRP and we will provide best service for you:

Accepting pre-submission inquiries through Email, Facebook, LinkedIn, Twitter, etc. A wide selection of journals (inclusive of 9 subjects, more than 200 journals)

Providing 24-hour high-quality service

User-friendly online submission system

Fair and swift peer-review system

Efficient typesetting and proofreading procedure

Display of the result of downloads and visits, as well as the number of cited articles Maximum dissemination of your research work

Submit your manuscript at: http://papersubmission.scirp.org/

Or contact jsea@scirp.org 